\title{
Azot gazı varlı̆̆ında yapılan ısıl işlemin kavak odununun bazı mekanik özellikleri üzerine etkileri
}

\author{
Hasan Orhana (iD, Bekir Cihad Bal ${ }^{\mathrm{b}, *}$ (it)
}

\begin{abstract}
Özet: $\mathrm{Bu}$ çalışmada, azot gazı varlığında yapılan ısıl işlemin, kavak (Populus subsps.) odununun bazı mekanik özellikleri üzerine etkileri belirlenmiştir. Isı transfer aracı olarak azot gazı ve hava olmak üzere iki farklı isı transfer aracı kullanılmış ve 1sıl işlemin bazı mekanik özellikler üzerine etkisi araştırılmıştır. Bu çalışmada, bir gruba ön işlem olarak vakumla odun boşluklarındaki havanın uzaklaştırılması ve yerine azot gazı transferi yapılmıştır. Sonra, ısıl işlem uygulanmıştır ve bu ön işlemin etkisi de belirlenmiştir. Laboratuvar denemelerinde statik eğilme direnci, eğilmede elastikiyet modülü, şok direnci gibi mekanik özellikler araştırılmıştır. Elde edilen bulgulara göre; 1sıl işlemin, kavak odununun mekanik özellikleri üzerine etkili olduğu belirlenmiştir. Eğilme direnci ve şok direnci ısıl işlem sonrası azalırken, elastikiyet modülünün bir miktar arttığı belirlenmiştir. Azot gazı varlığında yapılan ısıl işlemin mekanik özelikler üzerine etkisinin, hava varlığında yapılanlara göre daha az olduğu tespit edilmiş̧ir..
\end{abstract}

Anahtar kelimeler: Isıl işlem, Kavak odunu, Azot gazı, Mekanik özellikler

\section{Effects of heat treatment in the presence of nitrogen gas on some mechanical properties of poplar wood}

\begin{abstract}
In this study, the effects of heat treatment performed in the presence of nitrogen gas on some mechanical properties of poplar (Populus subsps.) wood were determined. Two different heat transfer media, nitrogen gas and air, were used as heat transfer media, and the effect of heat treatment on some mechanical properties was investigated. In this study, as a pre-treatment, the air in the wood cavities was removed by vacuum and nitrogen gas was transferred instead in a group. Then, heat treatment was applied and the effect of this pre-treatment was also determined. In laboratory experiments, mechanical properties such as static bending strength, modulus of elasticity in bending, impact bending were investigated. According to the data obtained; it was determined that heat treatment has an effect on the mechanical properties of poplar wood. While the bending strength and impact bending decreased after heat treatment, it was determined that the elastic modulus increased a little. It has been determined that the effect of heat treatment in the presence of nitrogen gas on mechanical properties is less than those performed in the presence of air.
\end{abstract}

Keywords: Heat treatment, Poplar wood, Nitrogen gas, Mechanical properties

\section{Giriş}

Günümüzde 1sıl işlem prosesi bir odun modifikasyon yöntemi olarak yaygın bir şekilde kullanılmaktadır. Birçok faktör 1sıl işlemin sonuçları üzerine etkilidir. Bu faktörler; sıcaklık, işlem süresi, 1sı transfer aracı, odun türü (yumuşak odun-sert odun), başlangıç rutubet miktarı, odun yoğunluğu ve odunun ekstraktif madde miktarıdır. Günümüzde, 1s1 transfer aracı olarak, su buharı, hava, bitkisel yağlar ve azot gazı kullanan birçok farklı endüstriyel ısıl işlem metodu geliştirilmiştir (Esteves ve Pereira, 2009; Korkut ve Kocaefe, 2009).

Odunun mekanik özellikleri; ağaç malzemenin boyut ve şekil değişmeleri, gerilme ve kırılmalara yol açan mekanik cinsten diş kuvvetlere karşı koyma durumunu belirtmektedir. Bir malzeme olarak odunun, diş kuvvetlerin etkilerine karşı koyması, kuvvetin büyüklüğüne, yönüne, çeşidine ve zamanına bağlıdır. Ayrıca, ağaç malzemenin şekli de karşı koyma gücünü etkilemektedir (Bozkurt ve Erdin, 1997). Kuvvetin tesir ediş şekline (uygulama şekli) göre 4 farklı yükleme şekli vardır. Bunlar; devamlı ve yavaş yavaş artan statik yüklemeler, ani şok şeklindeki dinamik yüklemeler, yeknesak ve uzun süreli yorma yüklemeleri ve tesir yönü tekdüze olarak değişen değişken yüklemeler şeklinde olduğu bildirilmiştir (Örs ve Keskin, 2001).

Odunun kimyasal, fiziksel, mekanik özellikleri, biyolojik dayanıklılı̆̆ı, estetik görünüş özellikleri ve ses özellikleri odunun kullanım yerlerini belirlerken göz önünde bulundurulan önemli özelliklerindendir. Ayrica, odunun maliyeti bu kullanım yerini belirlerken etkili olan faktörlerden birisidir. Estetik bakımdan üstün olan ve genelde mobilya ve iç mekân elemanlarında bu özelliği sebebiyle kullanılan ağaç türlerinin odunlarından elde edilen bu elemanlar fiyat olarak diğerlerine göre yüksektir. Bunun yayında, bir ağaç türünün odununun maliyetinin yüksek ya da düşük olmasına o ağaç türünün yetişme süreside etki

\footnotetext{
$\llbracket$ a Kahramanmaraş Sütçü İmam Üniversitesi, Fen Bilimleri Enstitüsü, Kahramanmaraș, Türkiye

b Kahramanmaraş Sütçü İmam Üniversitesi, Teknik Bilimler Meslek Yüksekokulu, Malzeme Bölümü, Kahramanmaraş, Türkiye

Corresponding author (İletişim yazarı): bcbal@ hotmail.com

$\checkmark \quad$ Received (Geliş tarihi): 07.03.2021, Accepted (Kabul tarihi): 14.06.2021
}

Citation (Atıf): Orhan, H., Bal, B.C., 2021. Azot gazı varlığında yapılan ısıl işlemin kavak odununun bazı mekanik özellikleri üzerine etkileri. Turkish Journal of Forestry, 22(2): 165170 . DOI: $\underline{10.18182 / \mathrm{tjf} .892685}$ 
etmektedir. Kavak, söğüt, bazı çam türleri, pavlonya ve okaliptüs türleri hızlı büyüyen ağaç türleridir ve genelde maliyetleri düşüktür. Bu ağaç türlerinin odunları hammadde olarak birçok farklı endüstride kullanılmaktadır. Bu ağaç türlerinin odunları yapacak odun olarak farklı alanlarda kullanılması gerekirse farklı metotlarla modifiye edilerek veya koruma işlemleri uygulayarak kullanılmaktadır. Isıl işlem modifikasyon yöntemi bu yöntemlerden birisidir.

Bu güne kadar 1sıl işlem modifikasyonu üzerine yapılan bilimsel çalışmalarda, ısıl işlem modifikasyonu uygulanan odunun daralma-genişleme özelliklerinin iyileştiği (Bal, 2016; Taşdelen vd., 2019), biyolojik dayanıklılığının arttığ1 ve daha dayanıklı hale geldiği (Jämsä ve Viitaniemi, 2001; Esteves ve Pereira, 2009; Candelier vd., 2013a; Düzkale ve Bektaş, 2019), renginin değiş̧tiği (Yaşar, 2009; Ayata vd., 2018; Karamanoğlu ve Kaymakçı, 2018; Ayata, 2020; Yazıcı ve Özlüsoylu, 2020), su almasının azaldığı (Bal, 2013; Taşdelen vd., 2019) ve bu olumlu iyileşmelerin yanında mekanik özelliklerinin azaldığı (Calonego vd., 2012; Candelier vd., 2013b; Bal ve Bektaş, 2013; Bal, 2014; Bal, 2018) bildirilmiştir. $\mathrm{Bu}$ nedenle, 1sıl işlem metotları üzerinde yapılan çalışmalarda mekanik özelliklerin azalmasını önleyen veya en aza indiren bir 1sıl işlem yöntemi geliştirebilmek önem arz etmektedir.

$\mathrm{Bu}$ çalışmada, kavak odunundan hazırlanan test örneklerinin azot gazı varlığında yapılan ısıl işlem sonrası, eğilme direnci, elastikiyet modülü ve şok direncinde (dinamik eğilme direnci) meydana gelen değişmelerin belirlenmesi amaçlanmıştır.

\section{Materyal ve yöntem}

\subsection{Materyal}

Bu çalışmada, deneme materyali olarak kavak (Populus subsps.) odunu kullanılmıştır. Kavak odunu Kahramanmaraş ili, Küçüknacar köyünden tomruk olarak elde edilmiştir. Tomruklar bir kereste atölyesinde biçilmiş ve keresteye dönüştürülmüştür. Biçme işlemi TS 2470 (1976)'ya göre yapılmıştır.

Deneylerde kullanılmak üzere belirlenen $300 \mathrm{~cm}$ uzunluğundaki kavak tomrukları kereste atölyesine taşınmıştır. Beş farklı tomruk, önce öz kısmı tam ortada kalacak şekilde Şekil 1'de görüldüğü gibi 10 x 10 x $300 \mathrm{~cm}$ (kalınlık x genişlik x uzunluk) ölçülerinde biçilmiştir. Sonra bu parçalardan $2.5 \times 10 \times 150 \mathrm{~cm}$ boyutlarında tahtalar elde edilmiştir.

$\mathrm{Bu}$ tahtalar düzgün bir şekilde istif edilmiş ve yapay havalandırma ile kurumaları sağlanmıştır. Sonra, oda şartlarında 4 hafta kurutma yapıldıktan sonra, 2 × 2 x 150 $\mathrm{cm}$ olacak şekilde çıtalara kesilmiştir. Elde edilen bu çıtalar yaklaşık 1 ay süre ile oda şartlarında şartlandırılmıştır. Sonra eğilme direnci ve şok direnci için gerekli olan test örnekleri bu çıtalardan 2 x 2 x $30 \quad \mathrm{~cm}$ ölçüsünde hazırlanmıştır. Her bir grup için 33 adet test örneği hazırlanmıştır. Çıtalardan art arda kesilen her bir test örneği farklı bir test grubuna dâhil edilmiştir. Böylece her bir çıtadan her bir test grubu için bir tane test örneği kesilmiştir. Böylece test grupları arasında odunun kendi doğal yapısından kaynaklanan farlılıklar en aza indirilmeye çalışılmıştır.

İnert gazlar, genel olarak istenmeyen kimyasal reaksiyonların test örneğini etkilemelerini önlemek için kullanılır. Bu nedenle yapılan denemelerde inert bir gaz olan azot gazı kullanılmıştır. Kullanılan azot gazı, Kahramanmaraş'ta faaliyet gösteren özel bir firmadan (OKNAL Sınaî ve Tıbbi Gazlar) tedarik edilmiştir.

\subsection{Yöntem}

Denemelerde kullanılmak üzere dört farklı test grubu hazırlanmıştır. Çizelge 1'de görülebileceği gibi, bu gruplardan 1 numaralı grup kontrol grubu olarak 2, 3 ve 4 numaralı gruplar ise deney grupları şeklinde planlanmıştır. 2 numaralı grup test örnekleri normal atmosfer şartlarında $210^{\circ} \mathrm{C}$ de 3 saat işlem görmüştür. 3 numaralı gruptaki test örnekleri ise azot atmosferinde $210^{\circ} \mathrm{C}$ de ve 3 saat işlem görmüştür. 4 Numaralı gruptaki test örnekleri ise önce 3 saat vakum uygulanarak odun boşluklarındaki hava alınmaya çalışılmış ve sonra etüv içerisine azot gazı verilerek ön işlem yapılmış ve sonra 3 saat $210^{\circ} \mathrm{C}$ de işlem görmüştür. Böylece çalışma sonunda, kontrol grubu ile karşılaştırılarak hem sıcaklığın hem azot gazının ve hem de azot gazı ile ön işlemin farkları tespit edilmeye çalışılmıştır.

Statik eğilme direnci denemeleri TS 2474 (1976)'ya ve eğilmede elastikiyet modülü TS 2478 (1976)'ya göre yapılmıştır. Test örnekleri 2 x 2 x $30 \mathrm{~cm}$ boyutlarında hazırlanmıştır. Testlerde mesnet açıklığı $24 \mathrm{~cm}$ olarak ayarlanmıştır. Kuvvet teğet yönde uygulanmıştır. Testlerin yapılmasında ALŞA marka hidrolik prensiple çalışan bir test cihazı kullanılmıştır. Şok direnci testleri TS 2477 (1976)'ya göre 2 × 2 x $30 \mathrm{~cm}$ 'lik test örnekleri üzerinde ve ALŞA marka şok direnci test cihazı ile yapılmıştır.
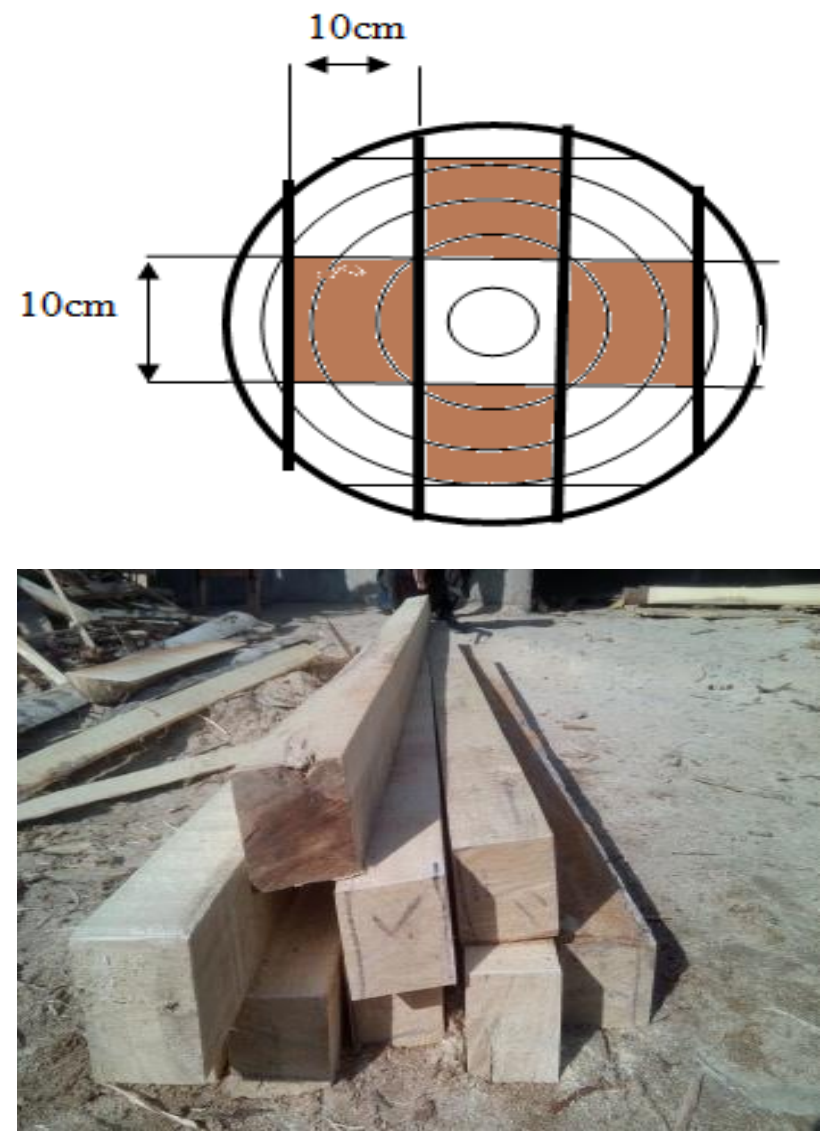

Şekil 1. Tomruklardan elde edilen parçalar 
Çizelge 1. Deneme planı ve grupların şartları

\begin{tabular}{|c|c|c|c|}
\hline 1. Grup & 2. Grup & 3. Grup & 4. Grup \\
\hline Kontrol Grubu & Normal şartlar altında & Azot gazı altında & Azotla ön işlem ve azot gazı altında \\
\hline İşlem yok & $\begin{array}{c}210^{\circ} \mathrm{C} \text { 'de } 3 \text { saat } 1 \text { sil işlem } \\
\text { uygulandı }\end{array}$ & $\begin{array}{c}210^{\circ} \mathrm{C}^{\prime} \text { de } 3 \text { saat } 1 \text { ssl işlem } \\
\text { uygulandı }\end{array}$ & $\begin{array}{c}3 \text { saat ön işlem ve } 210^{\circ} \mathrm{C} \text { 'de } 3 \text { saat } \\
\text { 1sıl işlem uygulandı }\end{array}$ \\
\hline
\end{tabular}

Isıl işlem uygulanmasında 64 litre kapasiteli JSR marka bir vakumlu etüv kullanılmıştır. Vakumlu etüve azot gazı ve vakum pompası bağlantısı Şekil 2'de görüldüğü gibi yapılmıştır. Normal atmosfer şartlarında yapılan 2 numaralı grubun isıl işlem uygulaması yapılırken vakum ve azot gazı kullanılmamıştır. 3 numaralı ve 4 numaralı gruplarda ise kapak kapatıldıktan sonra vakum uygulanmış ve dış atmosfer ile bağlantı kesilmiștir. Sonra, etüv içerisine azot gazı verilmiştir. Vakum azaldıkça tekrar vakum pompası çalıştırılmış ve sonra tekrar azot gazı beslenmiştir. Her üç deney grubunda da toplam isıl işlem süresi isıtma periyodu dahil 3 saat uygulanmıştır. Bu sürenin sonunda test örnekleri etüvden çıkarılmış ve oksijenle temas etmesini önlemek için bir naylon poșete bırakılmış, sonra bu şekilde soğutulmuştur. Soğutma işlemi sonrası yaklaşık 4 hafta klima dolabında $20^{\circ} \mathrm{C}$ sıcaklık ve $\% 65$ bağıl nem şartlarında kondisyonlanmıştır.

\subsubsection{Istatistik analizlerin yapılması}

Laboratuvar denemeleri sonrası, mekanik özelliklerle ilgili testlerden elde edilen bulgular Excel programına kaydedilmiş ve düzenlenmiștir. Bazı istatistik değerler (aritmetik ortalama, standart sapma, maksimum değer ve minimum değer) bu program vasıtasıyla elde edilmiştir. Gruplar arasında önemli bir fark olup olmadı $\breve{g}_{1}$ basit varyans analizi ile (One-Way ANOVA) SPSS 13.0 programında $\% 95$ güven aralığında belirlenmiştir. Gruplar arasında fark olduğu belirlendiğinde ise hangi grupların diğerlerinden farklı olduğu Duncan çoklu ayrım testi ile belirlenmiştir. Elde edilen istatistik sonuçları ilgili çizelgelerde gösterilmiştir.

\section{Bulgular ve tartışma}

Testler sonucunda elde edilen eğilme direnci, eğilmede elastikiyet modülü ve şok direncine ait istatistiki değerler Çizelge 2'de verilmiştir. Çizelge incelendiğinde genel olarak eğilme direnci ve şok direncine ait kontrol grubu test örneklerinden, deney grubu test örneklerine göre daha yüksek mekanik özellikler elde edildiği görülmektedir. Ancak eğilmede elastikiyet modülü değerleri, deney grubu test örneklerinde kontrol grubu test örneklerinden daha yüksek ölçülmüştür. Çizelgede verilen deney grubu tam kuru yoğunluk değerleri kontrol grubuna göre biraz daha düşüktür.

Çizelge 2'de verilen eğilme direncine ait istatistik değerler incelendiğine en yüksek aritmetik ortalamanın kontrol grubunda ölçüldüğü en küçük ortalamanın ise normal atmosfer şartlarında yapılan 2 numaralı grupta ölçüldüğü görülmektedir. 3 numaralı ve 4 numaralı gruplarda elde edilen eğilme direnci değerleri 2 numaralı gruptan elde edilenden biraz daha yüksektir. Eğilme direnci verilerinde dört grup arasında bir fark olup olmadığını belirlemek için ANOVA testi yapılmıș ve sonuçlar aşağıda Çizelge 3'de verilmiştir. Çizelgede verilen bu ANOVA testi sonucuna göre gruplar arasında önemli seviyede $(\mathrm{P}<0.001)$ farklılık olduğu görülmektedir.

Çizelgede verilen elastikiyet modülüne ait değerler incelendiğinde genel olarak kontrol grubu test örneklerine göre deney grubu test örneklerinin elastikiyet modülü değerleri biraz daha büyük ölçülmüştür. En yüksek elastikiyet modülü ise 3 numaralı grupta azot gazı atmosferinde işlem gören test örneklerinde belirlenmiştir. Azot gazı ile işlem gören 3 ve 4 numaralı gruplar arasındaki fark çok küçüktür. Bu gruplar arasında fark olup olmadığını belirlemek için ANOVA testi yapılmış ve elde edilen sonuçlar Çizelge 3'de verilmiştir. Çizelgede verilen bu sonuçlara göre elastikiyet modülü grupları arasında önemli seviyede $(\mathrm{P}<0.001)$ farklılık bulunmaktadır.

Çizelgede 2'de verilen deney grubu test örneklerinin şok direnci değerleri kontrol grubuna göre daha düşüktür. Bir diğer deyişle, uygulanan ısıl işlemin, şok direnci üzerinde yaklaşık olarak \%50 düzeyinde azalmaya sebep olduğu görülmektedir. En düşük şok direnci $0.218 \mathrm{kgm} / \mathrm{cm}^{2}$ olarak 2 numaralı grupta ölçülmüştür. 3 numaralı grup ile 4 numaralı grup arasında küçük bir farklılık olduğu görülmektedir. $\mathrm{Bu}$ verilere göre; gruplar arasındaki farkl1lıklar, Çizelge 3'de görülebileceği gibi, istatistiksel olarak önemli düzeydedir $(\mathrm{P}<0.001)$.

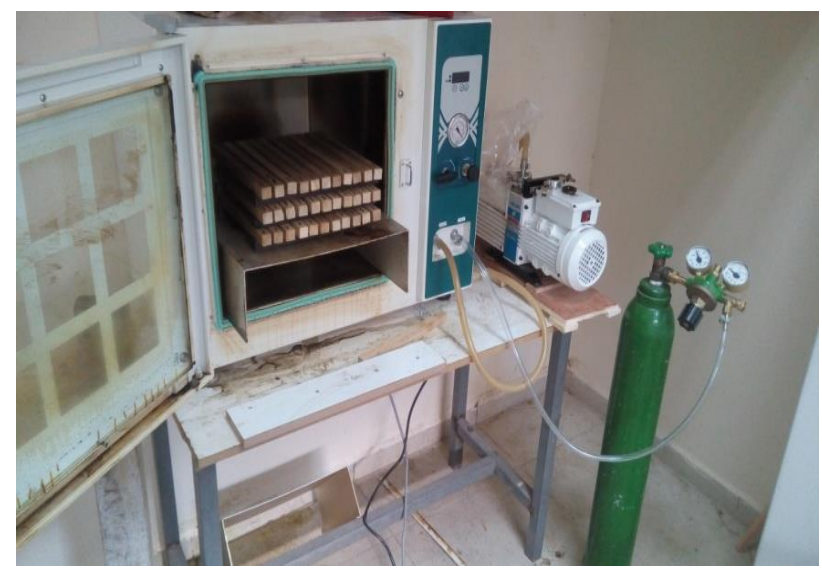

Şekil 2. Isıl işlem uygulaması yapılan vakumlu etüv, vakum pompası ve azot gazı tüpü 
Çizelge 2. Mekanik özeliklere ait bulgular (Orhan 2017)

\begin{tabular}{|c|c|c|c|c|c|}
\hline Grup & İD & TKY kg/m $\mathrm{m}^{3}$ & $\mathrm{ED}\left(\mathrm{N} / \mathrm{mm}^{2}\right)$ & $\mathrm{EM}\left(\mathrm{N} / \mathrm{mm}^{2}\right)$ & ŞD $\left(\mathrm{kgm} / \mathrm{cm}^{2}\right)$ \\
\hline \multirow{4}{*}{ 1.grup ${ }^{*}$} & $\mathrm{x}$ & 378 & $62,8 \mathrm{~A}$ & $4214,2 \mathrm{~B}$ & $0,528 \mathrm{~A}$ \\
\hline & ss & 24 & 4.1 & 700.1 & 0.109 \\
\hline & mak & 466 & 70.3 & 5430.2 & 0.718 \\
\hline & $\min$ & 342 & 53.2 & 2550.7 & 0.237 \\
\hline \multirow{4}{*}{ 2.grup } & $\mathrm{x}$ & 361 & $51.7 \mathrm{C}$ & $4684.7 \mathrm{~A}$ & $0.218 \mathrm{C}$ \\
\hline & ss & 24 & 5.2 & 580.2 & 0.048 \\
\hline & mak & 450 & 62.0 & 6236.5 & 0.307 \\
\hline & $\min$ & 313 & 36.8 & 3547.5 & 0.141 \\
\hline \multirow{4}{*}{ 3.grup } & $\mathrm{x}$ & 365 & $55.4 \mathrm{C}$ & 4919.9A & $0.241 \mathrm{~B}$ \\
\hline & ss & 22 & 6.1 & 825.4 & 0.046 \\
\hline & mak & 412 & 66.5 & 6576.1 & 0.345 \\
\hline & $\min$ & 320 & 39.7 & 2460.4 & 0.163 \\
\hline \multirow{4}{*}{ 4.grup } & $\mathrm{x}$ & 366 & $55.8 \mathrm{~B}$ & 4813.7A & $0.248 \mathrm{~B}$ \\
\hline & ss & 17 & 4.4 & 677.9 & 0.035 \\
\hline & mak & 402 & 63.6 & 6618.3 & 0.320 \\
\hline & $\min$ & 340 & 47.8 & 3635.1 & 0.188 \\
\hline
\end{tabular}
ortalama, ss: standart sapma, mak: maksimum değer, min: minimum değer, TKY: tam kuru yoğunluk, ED: eğilme direnci, EM: elastikiyet modülü, ŞD: şok direnci

Çizelge 3. Eğilme direnci, elastikiyet modülü ve şok direncine ait ANOVA testi sonuçları

\begin{tabular}{|c|c|c|c|c|c|c|}
\hline Bağımlı değişken & Varyans kaynağ 1 & Kareler toplamı & Serbestlik derecesi & Ortalama kareler & $\mathrm{F}$ & Önem düzeyi \\
\hline \multirow{3}{*}{ ED } & Gruplar arası & 2092 & 3 & 697 & 27.86 & $0.000^{*}$ \\
\hline & Gruplar içi & 3078 & 123 & 25 & & \\
\hline & Toplam & 5170 & 126 & & & \\
\hline \multirow{3}{*}{ EM } & Gruplar arası & 9393367 & 3 & 3131122 & 6.38 & $0.000^{*}$ \\
\hline & Gruplar içi & 60341401 & 123 & 490580 & & \\
\hline & Toplam & 69734768 & 126 & & & \\
\hline \multirow{3}{*}{ ŞD } & Gruplar arası & 2 & 3 & 0.67 & 152.79 & $0.000^{*}$ \\
\hline & Gruplar içi & 0.52 & 120 & 0 & & \\
\hline & Toplam & 2.52 & 123 & & & \\
\hline
\end{tabular}

*İstatistiksel olarak çok ileri düzeyde önemli.

Şok direnci test örnekleri, test sonrası kırılma bölgesindeki kıymık uzunluğuna göre incelenmiştir. TS 2477 (1976) numaralı standartta belirtilen kıymık uzunluğu kriterine göre, 3 mm'den kısa kıymıklı ise gevrek ve 3 mm'den uzun kıymıklı ise esnek olarak nitelendirilmektedir. Şok direnci testi sonrası test öneklerinin görüntüsü aşağıda Şekil 3'de verilmiştir. Şekilde verilen fotoğraf incelendiğinde, şok direnci test örneklerinin kırılma şekilleri bakımından birbirlerinden farklılık gösterdiğ görülmektedir. Özellikle kontrol grubu test örneklerinin kırılma şekilleri uzun kıymıklıdır. Diğer gruplarda ise genel olarak kısa kıymıklı bir kırılma şekli gözlemlenmiştir. Özellikle, normal atmosfer şartlarında 1 sıl işlem uygulanan 2 numaralı gruptaki test örneklerinin diğer 3 ve 4 numaralı gruplardaki test örneklerinden daha kısa kıymıklı bir kırılma oluşturdukları görülmektedir. $\mathrm{Bu}$ duruma göre, kontrol grubu test örneklerinin esnek, 1sıl işlem sonrası deney gruplarına ait test örneklerinin gevrek bir özellik gösterdikleri söylenebilir.

Yapılan önceki çalışmalarda, 1sıl işlem uygulaması sonrası test örneklerinin mekanik özelliklerinin değiştiği, özellikle eğilme direnci ve şok direncinin azaldığ araştırmada ortaya konmuştur (Borrega ve Karenlampi, 2008; Mburu vd., 2008; Korkut ve Kocaefe 2009; Esteves ve Pereira, 2009; Bal ve Bektaş, 2013; Bal, 2014). Ancak yapılan bazı önceki çalışmalarda, elastikiyet modülünün nasıl değiştiğine dair farklı bazı sonuçlar rapor edilmiştir. $\mathrm{Bu}$ çalışmaların bazılarında elastikiyet modülünün azaldığ (Korkut vd., 2008; Bal, 2014), bazılarında değişmediği (Bekhta ve Niemz, 2003) ve bazılarında ise arttığı (Santos,
2000) yönünde farklı sonuçlar bildirilmiştir. Bu gibi farklı sonuçlar elde edilmesinin birçok farklı sebebi bulunmaktadır. Odun üzerine yapılan mekanik özelliklerle ilgili testlerde ağaç türü, rutubet ve yoğunluk mekanik özellikleri etkileyen en önemli özelliklerdendir (Kollman ve Cote, 1968; Örs ve Keskin, 2001). Bunların yayında diğer bazı özellikler ısıl işlemin etkisini değiştirmektedir. Bunlar ise; test grupları arasında homojenliğin sağlanamaması, işlem şartları, odun özellikleri, 1sıl işlem öncesi ve sonrası işlemler şeklinde sıralanabilir. $\mathrm{Bu}$ nedenle, mekanik özelliklerle ilgili farklı bazı sonuçların bulunması, malzemeden kaynaklanan sebeplerdir. Ancak, bazı araştırmacılar tarafından elastikiyet modülünün artmasının sebebinin ligninin 1 ș1 işlem esnasında dallanması ve selülozun kristalleşmesi olarak gösterilmektedir (Kocaefe vd., 2008). Mekanik özellikler ile ilgili olarak tespit edilen diğer bir önemli konuda, 1sıl işlem uygulamasından en fazla etkilenen mekanik özelliğin şok direnci olduğudur. Yapılan bu çalışma sonunda, şok direnci her üç deney grubunda kontrol grubu test örneklerine göre şok direncinde yaklaşık \%50 kadar azalma meydana gelmiştir. $\mathrm{Bu}$ durum, malzemenin esnek ya da gevrek olması ile ilgili bir konudur. Isıl işlem gören ağaç malzemenin gevrekliği son derece artmaktadır. Daha kırılgan bir hale gelmektedir. Bu konuda yapılan önceki çalışmalarda benzer sonuçlar rapor edilmiş ve en fazla etkilenen mekanik özelliğin şok direnci olduğu bildirilmiştir (Korkut vd., 2008; Bal ve Bektaş 2013; Bal, 2014). 


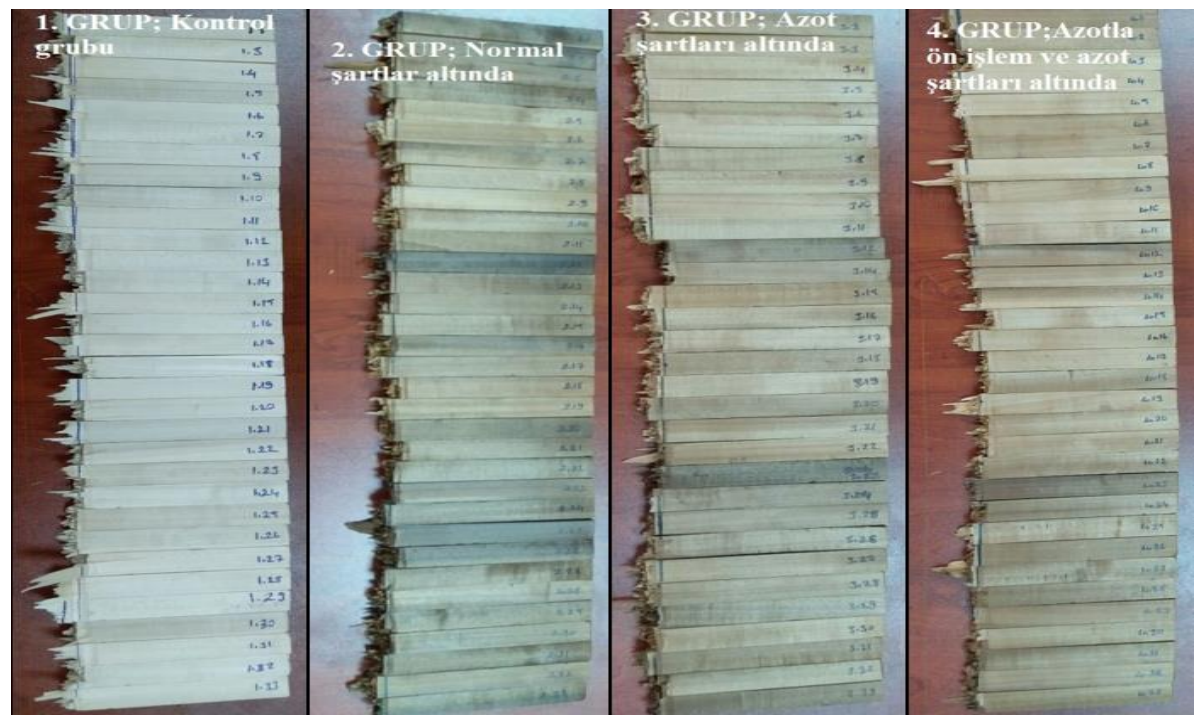

Şekil 3. Şok direnci test örnekleri test sonrası görüntüsü

\section{Sonuç}

$\mathrm{Bu}$ çalışmada, kavak odunundan elde edilen test örneklerinin farklı şartlarda 1sıl işlem uygulaması sonrası bazı mekanik özelliklerinde meydana gelen değişmeler incelenmiştir. Elde edilen bulgulara göre varılan sonuçlar şu şekilde sıralanabilir;

- Eğilme direnci, elastikiyet modülü ve şok direncinin 1sıl işlem uygulamasından farklı şekillerde etkilendiği belirlenmiştir. Eğilme direnci ve şok direnci isıl işlem sonrası azalırken, elastikiyet modülünün bir miktar arttığ belirlenmiştir. Kontrol grubuna göre en fazla azalan eğilme direnci ve şok direnci grubu normal atmosfer şartlarında yapılan ısıl işlem grubunda ölçülmüştür.

- Deney gruplarından azot gazı atmosferinde ön işlem gören grupla, ön işlem uygulanmayan grup arasında fark vardır, ancak bu fark istatistiksel olarak önemsizdir.

- Kontrol grubuna kiyasla deney grubu test örneklerinin renkleri gözlemlendiğinde, test örneklerinin renklerinde koyulaşma olduğu görülmektedir. En fazla renk değişmesi normal atmosfer şartlarında yapılan isıl işlem uygulamasında görülmektedir.

- Normal atmosfer basincinda ve hava atmosferinde yapılan ısıl işlem uygulamasına göre azot gazı atmosferinde yapılan denemelerden mekanik özellikler için daha iyi sonuçlar elde edilmiştir.

\section{Açıklama}

$\mathrm{Bu}$ makale, Hasan ORHAN isimli yazarın "Kavak odununun bazı fiziksel ve mekanik özellikleri üzerine azot gazı varlığında yapılan isıl işlemin etkilerinin belirlenmesi" başlıklı yüksek lisans tezinden hazırlanmıştır. Bu çalışma, Kahramanmaraş Sütçü İmam Üniversitesi Bilimsel Araştırma Projeleri Koordinasyon Birimince desteklenmiştir. Proje Numarası: 2017/1-60 YLS.

\section{Kaynaklar}

Ayata, Ü., Gürleyen, T., Gürleyen, L., 2018. Effect of heat treatment on color and glossiness properties of zebrano, sapelli and merbau woods. Mobilya ve Ahşap Malzeme Araştırmaları Dergisi, 1(1): 11-20. DOI: 10.33725/mamad.428913.

Ayata, Ü., 2020. Ayous odununun bazı teknolojik özelliklerinin belirlenmesi ve isıl işlemden sonra renk ve parlaklık özellikleri. Mobilya ve Ahşap Malzeme Araştırmaları Dergisi, 3(1): 22-33. DOI: $10.33725 /$ mamad.724596.

Bal, B.C., 2013. A comparative study of the physical properties of thermally treated poplar wood and plane wood. BioResources, 8(4): 6493-6500. DOI: 10.15376/biores.8.4.6493-6500

Bal, B.C., 2014. Some physical and mechanical properties of thermally modified juvenile and mature black pine wood. European Journal of Wood and Wood Products, 72: 61-66. DOI: 10.1007/s00107-013-0753-9.

Bal, B.C., Bektaş, İ, 2013. The Effects of heat treatment on some mechanical properties of juvenile wood and mature wood of Eucalyptus grandis. Drying Technology, 31(4): 479-485. DOI: 10.1080/07373937.2012.742910.

Bal, B.C., 2016. Sicak bitkisel yağ ile muamele edilen Toros göknarı odununun bazı fiziksel özellikleri. Kahramanmaraş Sütçü İmam Üniversitesi Mühendislik Bilimleri Dergisi, 19(2): 20-26. DOI: 10.17780/ksujes.58765

Bal, B.C., 2018. A comparative study of some of the mechanical properties of pine wood treated in vacuum, nitrogen, and air atmospheres. Bioresources, 13(3): 5504-5511.

Bekhta, P., Niemz, P., 2003. Effect of high temperature on the change in color, dimensional stability and mechanical properties of spruce wood. Holzforschung, 57: 539-546. DOI: 10.1515/hf.2003.080.

Borrega, M., Karenlampi, P.P., 2008. Mechanical behaviour of heat-treated spruce (Picea abies) wood at constant moisture content and ambient humidity. Holz als Roh-und Werkstoff, 66: 63-69. DOI: 10.1007/s00107-007-0207-3.

Bozkurt, Y., Erdin, N., 1997. Ağaç Teknolojisi Ders Kitabı. İstanbul Üniversitesi Orman Fakültesi, Yayın no: 445, İstanbul.

Calonego, F.W., Severo, E.T.D., Ballarin, A.W., 2012. Physical and mechanical properties of thermally modified wood from $E$. Grandis. European Journal of Wood and Wood Products, 70(4): 453-460. DOI: 10.1007/s00107-011-0568-5. 
Candelier, K., Dumarçay, S., Pétrissans, A., Desharnais, L., Gérardin, P., Pétrissans, M., 2013a. Comparison of chemical composition and decay durability of heat treated wood cured under different inert atmospheres: Nitrogen or vacuum. Polymer degradation and Stability, 98(2): 677-681. DOI:10.1016/j.polymdegradstab.2012.10.022.

Candelier, K., Dumarçay, S., Pétrissans, A., Gérardin, P., Pétrissans, M., 2013b. Comparison of mechanical properties of heat-treated beech wood cured under nitrogen or vacuum. Polymer degradation and stability, 98(9):1762-1765. DOI: 10.1016/j.polymdegradstab.2013.05.026.

Düzkale, S.G., Bektaş, İ., 2019. Esmer çürüklük mantarına karşı 1sıl ișlem görmüș ve yoğunlaștırılmış kavak odununun biyolojik dayanımının araştırılması. Turkish Journal of Forestry, 20(4): 421-426. DOI: 10.18182/tjf.636671.

Esteves, B.M., Pereira, H.M., 2009. Wood modification by heat treatment: A review. BioResources 4(1): 370-404. DOI: 10.15376/biores.4.1.370-404.

Karamanoğlu, M., Kaymakçı, A., 2018. Higrotermal yaşlandırma işleminin 1sıl işlem görmüş kestane odununun renk ve sertlik özellikleri üzerine etkisi. Mobilya ve Ahşap Malzeme Araştırmaları Dergisi, 1(1): 31-37. DOI: 10.33725/mamad.429726.

Kocaefe, D., Shi, L.J., Yang, D.Q., Bouazara, M., 2008. Mechanical properties, dimensional stability, and mold resistance of heat-treated jack pine and apsen. Forest Products Journal, 58(6): 88-93.

Kollmann, F.F., Cote, Jr W.A., 1968. Principles of Wood Science and Technology, Volume I. Solid Wood, In Principles Of Wood Science and Technology. Springer-Verlag.

Korkut, S., Gündüz, G., Korkut, D.S., 2008. The effects of heat treatment on physical and technological properties and surface roughness of Camiyanı Black Pine (Pinus nigra Arn. subsp. pallasiana var. pallasiana) wood. Bioresource Technology, 99: 2275-2280. DOI: 10.1016/j.biortech.2007.05.015.

Korkut, S., Kocaefe, D., 2009. Isıl işlemin odun özellikleri üzerine etkisi. Düzce Üniversitesi Ormancılık Dergisi, 5(2): 11-34.

Mburu, F., Dumarçay, S., Bocquet, J.F., Petrissans, M., Gerardin, P., 2008. Effect of chemical modifications caused by heat treatment on mechanical properties of grevillea robusta wood. Polymer Degradation and Stability, 95(11): 2169-2174. DOI: 10.1016/j.polymdegradstab.2007.11.017.
Orhan, H., 2017. Kavak odununun bazı fiziksel ve mekanik özellikleri üzerine azot gazı varlığında yapılan isıl işlemin etkilerinin belirlenmesi. Yüksek Lisans Tezi, Kahramanmaraş Sütçü İmam Üniversitesi, Fen Bilimleri Enstitüsü, Kahramanmaraş.Örs, Y., Keskin, H., 2001. Ağaç Malzeme Bilgisi. Gazi Üniversitesi Ders Kitabı, Atlas Yayın Dağıtım, Ankara.

Jämsä, S., Viitaniemi, P., 2001. Heat treatment of wood-Better durability without chemicals. In: Rapp AO, editor. In: Review on heat treatments of wood. Cost Action E22. Proceedings of the special seminar, Antibes, France, Pp. 17-22

Santos, J.A., 2000. Mechanical behavior of eucalyptus wood modified by heat. Wood Science and Technology, 34(1): 3943. DOI: $10.1007 / \mathrm{s} 002260050006$.

Taşdelen, M., Can, A., Sivrikaya, H., 2019. Some physical and mechanical properties of maritime pine and poplar exposed to oil-heat treatment. Turkish Journal of Forestry, 20(3): 254-260. DOI: $10.18182 / \mathrm{tjf} .566647$.

TS 2470, 1976. Odunda fiziksel ve mekaniksel deneyler için numune alma metotları ve genel özellikler. Türk Standartları Enstitüsü, Ankara.

TS 2474, 1976. Odunun statik eğilme dayanımının tayini. Türk Standartları Enstitüsü, Ankara.

TS 2477, 1976. Odunun çarpmada eğilme dayanımının tayini. Türk Standartları Enstitüsü, Ankara.

TS 2478, 1976. Odunun statik eğilmede elastiklik modülünün tayini. Türk Standartları Enstitüsü, Ankara.

Yaşar, S., 2009. Kızılçam (Pinus brutia Ten.) ekstraktif maddelerinde 1sıl işlem uygulanması sonucu oluşan renk değişimleri üzerine araştırma. Turkish Journal of Forestry, 10(1): 95-100

Yazıcı, H., Özlüsoylu, İ., 2020. Hızlandırılmış yaşlandırmanın ısıl işlem uygulanmış Akdeniz defnesi (Laurus nobilis L.) odunun bazı yüzey özelliklerine etkisi. Turkish Journal of Forestry, 21(4): 468-474. DOI: 10.18182/tjf.809139. 